\title{
«Spatial Growth Volatility and Age-structured Human Capital Dynamics in Europe »
}

\author{
$\underline{\text { Auteurs }}$ \\ Mamata Parhi, Tapas Mishra \\ Document de Travail $n^{\circ} 2008$ - 4
}

Février 2008

Faculté des sciences économiques et de gestion

Pôle européen de gestion et d'économie (PEGE) 61 avenue de la Forêt Noire

F-67085 Strasbourg Cedex

Secétariat du BETA Géraldine Manderscheidt Tél. : (33) 0390242069 Fax : (33) 0390242070 manderscheidt@cournot.ustrasbg.fr

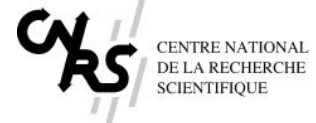
Nancy-Université

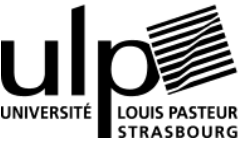




\title{
Spatial Growth Volatility and Age-structured Human Capital Dynamics in Europe
}

\author{
Mamata Parhi ${ }^{a}$ and Tapas Mishra ${ }^{b *}$ \\ a BETA, Université Louis Pasteur, \\ 61 avenue de la Forêt Noire, F-67085 Strasbourg, France \\ ${ }^{b}$ International Institute for Applied Systems Analysis (IIASA) \\ A-2361 Laxenburg, Austria
}

\begin{abstract}
In a semi-parametric spatial vector autoregressive setting this paper investigates the role of age-structured human capital on output comovements in Europe. Using the proportion of age-structured human capital growth and its degree of appropriations in output production as twin measures of distance, we find significant positive spatial growth volatility/persistence.
\end{abstract}

JEL Classification: C14, C31, E61, J11, O47

Key words: Spatial growth volatility, Non-linear growth, Age-structured human capital, Semi-parametric VAR.

\footnotetext{
*Corresponding author: T. Mishra. Tel: (43) 2236807303 Fax: (43) 223671313 . E-mail: mishra@iiasa.ac.at
} 


\section{Introduction}

The role of 'space', though was not central in traditional economic growth framework, has earned increasing prominence in the latest theoretical (e.g., Fujita and Thisse, 2002) and empirical (e.g., Conley and Dupor, 2003; Ertur and Koch, 2006, 2007, among others) literature. Taking cues from the theories of new economic geography, it has been widely established that spatial factor mobility and knowledge spillovers can potentially propel growth synergies/volatility to migrate from one economy to another (at least in the neighbourhood and albeit with a lag). Put simply, cross-country economic growth can be correlated. Latest empirical dissections (viz., Ertur and Koch, 2007) have rightly supported this claim by building empirically testable spatial growth models where interdependence among countries could be modeled via technological and human capital growth. An imposing feature of locational growth interdependence is that it could trigger high degree of persistence in international output (e.g., Durlauf, 1989; Raj, 1993; Levy and Dezhbakhsh, 2003; Mello and Guimaraes-Filho, 2007). Despite some contradictions, the literature points to the possible coordination failure in economic activities among different countries as major source of persistence. At international level, the evidence of varying degrees of persistence with some commonality in the degree of shock convergence in output (Mello and Guimaraes-Filho, 2007) further confirms that output shocks are correlated in space governed by a complex feedback mechanism and thus volatility (occurring due to either exogenous and/or endogenous shocks) in one economy would migrate to another. This in turn would induce high degree of non-linearity in growth across space.

While some recent research (viz., Ertur and Koch, 2007) have explicitly built empirical spatial growth models, very little has been researched on the nature and source of possible persistence in spatial output volatility and complementarity in growth and their implications for countries' policies at individual and collective level. We hold that correlation in cross-country growth can be linked to a common source of fluctuation such that possible growth volatility can be explicated by economic theoretic mechanisms viz., human capital and its recent extension - demography led human capital growth (e.g., Boucekkine et al., 2002). The relevance of the latter is quite pertinent in Europe where many economies are experiencing faster ageing, thus exerting enormous impact on their prospective human capital generation and long-run economic growth. Since many European countries share common socio-economic and demographic dynamics, it is pertinent to ask: Are European countries complementary in growth (at least in the neighborhood) with respect to levels of demographic change and (hence) human capital accumulation? Is the possible comovement caused by a common aggregate shock? Moreover, can a demography-based distance measure, viz., age-structured human capital appropriations in production explain the possible positive spatial correlation and non-linearity in spatial growth? If so, what lessons can we learn about policies promoting/optimising individual and collective economic welfare? In the framework of semi-parametric spatial Vector Autoregressive (VAR) setting (Chen and Conley, 2001), this paper attempts to answer these questions by examining a sample of 20 countries in Europe for the period 1970-2000.

\section{The Model}

We estimate a fully interconnected model with feedback effects in the semi-parametric SVAR framework of Chen and Conley (2001). The model is described by

$$
\mathbf{Z}_{t+1}=A\left(\mathbf{D}_{t}\right) \mathbf{Z}_{t}+\varepsilon_{t+1}, \quad \varepsilon_{t+1}=Q\left(\mathbf{D}_{t}\right) \mathbf{u}_{t+1}
$$


where $\mathbf{Z}_{t}=\left(Y_{1, t}, Y_{2, t}, \cdots, Y_{N, t}\right)^{\prime} \in \mathbb{R}^{N}$ is a vector stacking $\left\{Y_{i, t}\right\}_{i=1}^{N}$ with $Y_{t}=\left(X_{1, t}, \cdots, X_{N, t}\right)^{\prime} \in$ $\mathbb{R}^{N} .\left\{X_{i, t}: i=1, \cdots, N ; t=1, \cdots, T\right\}$ is described by the sample realizations of $N$ countries' variables at locations $\left\{s_{i, t}: i=1, \cdots, N ; t=1, \cdots, T\right\} . \mathbf{D}_{t}$ in the Eq. 1 is a stacked vector of distances (represented by a set of locations in $\mathbb{R}^{k}$ for country $i$ at time $t$ located at point $s_{i, t}$ ) between the $\left\{s_{i, t}\right\}_{i=1}^{N}$ defined for two points $i$ and $j$ as $\mathbf{D}_{t}(i, j)=\left\|s_{i, t}, s_{j, t}\right\|$ with $\|\cdot\|$ denoting the Euclidean norm. Assuming that the growth of a given country at $t+1$ denoted by $Y_{i, t+1}$ will depend not only on its own past (home externalities), but also nonparametrically on the performance of its neighbors (spatial spillovers effects), we model the joint process $\left\{\left(\mathbf{Z}_{t}, \mathbf{D}_{t}\right)\right.$ : $t=1, \cdots, T\}$ as a first order Markov process as in Chen and Conley (2001) which designs the evolution of $\mathbf{Z}_{t}$ according to Eq. 1 as above. $A\left(\mathbf{D}_{t}\right)$ is a $N \times N$ matrix whose elements are functions of age-structured human capital distances between countries. We assume that $\mathbf{u}_{t+1}$ is an i.i.d. sequence with $\mathbb{E}\left(\mathbf{u}_{t+1}\right)=0$ and $\mathbb{V}\left(\mathbf{u}_{t+1}\right)=I_{N}$. It follows that the conditional covariance matrix of $\varepsilon_{t+1}$ is $\mathbb{E}\left(\varepsilon_{t+1} \varepsilon_{t+1}^{\prime}\right)=Q\left(\mathbf{D}_{t}\right) Q\left(\mathbf{D}_{t}\right)^{\prime}:=\Omega\left(\mathbf{D}_{t}\right)$, which is also function of distances. In the specification (Eq. 1), the conditional mean $A\left(\mathbf{D}_{t}\right)$ and the conditional covariance $\Omega\left(\mathbf{D}_{t}\right)$ need to be estimated which have the following structure.

\section{Conditional means}

From (1), the conditional mean of $Y_{i, t+1}$ given $\left\{\mathbf{Z}_{t-l}, \mathbf{D}_{t-l}, l \geq 0\right\}$ is modelled as

$$
\mathbb{E}\left[Y_{i, t+1} \mid\left\{\mathbf{Z}_{t-l}, \mathbf{D}_{t-l}, l \geq 0\right]=\alpha_{i} Y_{i, t}+\sum_{j \neq i}^{N} f_{i}\left(\mathbf{D}_{t}(i, j)\right) Y_{j, t}\right.
$$

where the $f_{i}$ are continuous functions mapping from $(0, \infty)$ to $\mathbb{R}^{l}$. It follows that the conditional mean of $\mathbf{Z}_{t+1}$ given $\left\{\mathbf{Z}_{t-l}, \mathbf{D}_{t-l}, l \geq 0\right\}$ is $A\left(\mathbf{D}_{t}\right) \mathbf{Z}_{t}$, where

$$
A\left(\mathbf{D}_{t}\right)=\left(\begin{array}{cccc}
\alpha_{1} & f_{1}\left(\mathbf{D}_{t}(1,2)\right) & \cdots & f_{1}\left(\mathbf{D}_{t}(1, N)\right) \\
f_{2}\left(\mathbf{D}_{t}(2,1)\right) & \alpha_{2} & \cdots & f_{2}\left(\mathbf{D}_{t}(2, N)\right) \\
\vdots & \vdots & \vdots & \vdots \\
f_{N}\left(\mathbf{D}_{t}(N, 1)\right) & f_{N}\left(\mathbf{D}_{t}(N, 2)\right) & \cdots & \alpha_{N}
\end{array}\right)
$$

\section{Conditional covariances}

The conditional covariance of $\mathbf{Z}_{t+1}$ given $\left\{\mathbf{Z}_{t-l}, \mathbf{D}_{t-l}, l \geq 0\right\}$ is modelled as

$$
\Omega\left(\mathbf{D}_{t}\right)=\left(\begin{array}{cccc}
\sigma_{1}^{2}+\gamma(0) & \gamma\left(\mathbf{D}_{t}(1,2)\right) & \cdots & \gamma\left(\mathbf{D}_{t}(1, N)\right) \\
\gamma\left(\mathbf{D}_{t}(2,1)\right) & \sigma_{2}^{2}+\gamma(0) & \cdots & \gamma\left(\mathbf{D}_{t}(2, N)\right) \\
\vdots & \vdots & \vdots & \vdots \\
\gamma\left(\mathbf{D}_{t}(N, 1)\right) & \gamma\left(\mathbf{D}_{t}(N, 2)\right) & \cdots & \sigma_{N}^{2}+\gamma(0)
\end{array}\right)
$$

where $\gamma($.$) is assumed to be continuous at zero and is k$-dimensional isotropic covariance function. ${ }^{1}$ The choice of $\gamma$ ensures that $\Omega\left(D_{t}\right)$ is positive definite for any set of interpoint distance $D_{t}$ and any values of the $\sigma_{i}^{2} \geq 0$. Our interest lies in the shape of functions $f_{i}$ and $\gamma$. The model is estimated with $f_{i}$ specified to be common across countries, using least squares. We approximate $f$ as a linear combination of eight third order spline scaled to be evenly spaced over the support of the distance distribution (See Chen and Conley, 2001 for details). An important and desirable feature of Eq. 1 is that it does not assume $a$ priori parametric specification of neighborhood structure as is usually done in parametric spatial models.

\footnotetext{
${ }^{1}$ Isotropy means that the stationary random field (with indexes in $\mathbb{R}^{k}$ ) that generates the process is directional invariant.
} 


\section{Data and distance measure}

Per capita real GDP data (from Penn World Table 6.1) with Purchasing Power Parity at 1996 international US\$ is used as output measure. Output growth is calculated by their logarithmic differences. Using the IIASA/VID data base $^{2}$ we construct the distance measure based on agestructured human capital. Secondary educational attainment data for population age groups: 15-29, 30-49, 50-64 is utilized to construct two economic distance measures: (i) the proportion of human capital stock for three age-specific population over 1970-2000 (denoted by $D_{1}$ ) and (ii) the input share of human capital in the country's production over the same period (denoted by $D_{2}$ ). $D_{1}$ is constructed by calculating the average of the proportion of people (with secondary education or more) for each age-group over 30 years. For $D_{2}$, a two-sector production function with physical and human capital as inputs has been estimated. Elasticity estimates of human capital for each country are then used for the measure of $D_{2}$. Country locations $s_{i, t}$ are then identified with $D_{1}$ and $D_{2}$. Thus, two countries are close in the sense of $D_{1}$ if the proportion of human capital in the age-structured population for two countries is same, distant, otherwise. Similarly, two countries are close in the sense of $D_{2}$ if they utilize approximately same quantity of human capital in production. While the former induces productivity effects as the stock of human capital at each demographic level exerts varying productivity effects across country locations, the latter induces a scale effect in the economies (affecting production through knowledge creation). Time non-varying distance is assumed for simplicity, which could be reasonable, given the slow paced demographic changes.

\section{Empirical results}

Based on the model and data specifications described above, we explicate here the shapes of $f$ (estimating the output comovements) and $\gamma$ (indicating residual covariance comovements) with respect to the two distance metrics (in Figures 1 and 2). The solid line is our point estimate of $f$, plotted against the distances (in the $\mathrm{X}$-axis). The crosses represent $95 \%$ bootstrap confidence interval. Using the age-structured human capital distance, $D_{1}$ as in Fig. 1, we notice that the point estimates are large compared to Fig. 2 which uses the elasticity of input measure, $D_{2}$ (compare the $f$ functions). A significant positive dynamic spatial correlation at most distances is thus observed, which is an important indication of positive growth spill-over effects. Moreover, high degree of non-linear spatial growth comovement is observed for the distance $D_{2}$ with some degree of non-linearity in $D_{1}$ as well.

Notice that $D_{2}$ (Fig. 2) induces high degree of non-linearity in growth ( $f$ function) due to feedback effects in productivity movement across countries, the impacts of which are felt at varying time lags. Indeed, using $D_{1}$ we observe high complementarity in growth at lower distances which finds natural explanation in migration of productivity effects across countries as mentioned above. However, $D_{2}$ (Fig. 2) induces high degree of non-linearity in spatial growth ( $f$ function) for which growths are even found to be correlated at high distances. This could partially be due to the measure itself: $D_{2}$ is constructed from the stock of human capital in total population, which does not in stricto sensu explain the complex interaction effect from different levels of demographic-change-induced human capital accumulation on the economy. But this is clearly taken care of by $D_{1}$ where distance is constructed for each age-structured human capital

\footnotetext{
${ }^{2}$ The International Institute for Applied Systems Analysis and Vienna Institute of Demography data base is a unique and argued to be better than competing databases on educational attainment levels by age and sex for 120 countries in the period 1970-2000. See http://www.iiasa.ac.at/Admin/PUB/Documents/IR-07-011.pdf for details.
} 
accumulation thus outlining distinct and expected pattern in cross-country output comovement at varying distances.

Putting together, this confirms that countries' growth processes are complementary and can be explained by the demography-led human capital accumulation, indicating the centrality of the latter in the generation of spatial growth volatility. Since non-linear positive spatial correlation is observed for both distance metrics, we conjecture that both scale and productivity effects arising from the embedding of $D_{1}$ and $D_{2}$ in the regression (assuming feedback effect from demography to economic growth via human capital accumulation) could be behind the non-linearity.

The estimates of $\gamma$ (indicating covariances of residuals) divided by the country variance estimates are presented in right panels of Fig. 1 and 2. These normalized $\gamma$ estimate would be the sample spatial correlation if country variances were identical. Notice that $\gamma$ is quite large for $D_{2}$ and small but positive-constant for $D_{1}$. Moreover, $\gamma$ is found to decline monotonically with distance (in Fig. 2) and then remains at zero level (after fast decay) for higher distances (Fig. 1). Taking together, there is (strong) evidence that shocks in our VAR model are spatially correlated as a function of distance.

To conclude, significant cross-country output comovements within European countries are found suggesting possible stochastic shock movements across them. The evidence of spatial growth complementarity could also be generalized for other countries sets in a similar vein. Based on the evidence, it might be imperative to devise collective European policies to successfully check spatial growth volatility. A long term policy planning based on a greater co-ordination among individual countries with a common demographic/human capital management agenda could be useful in enhancing individual and collective social welfare.
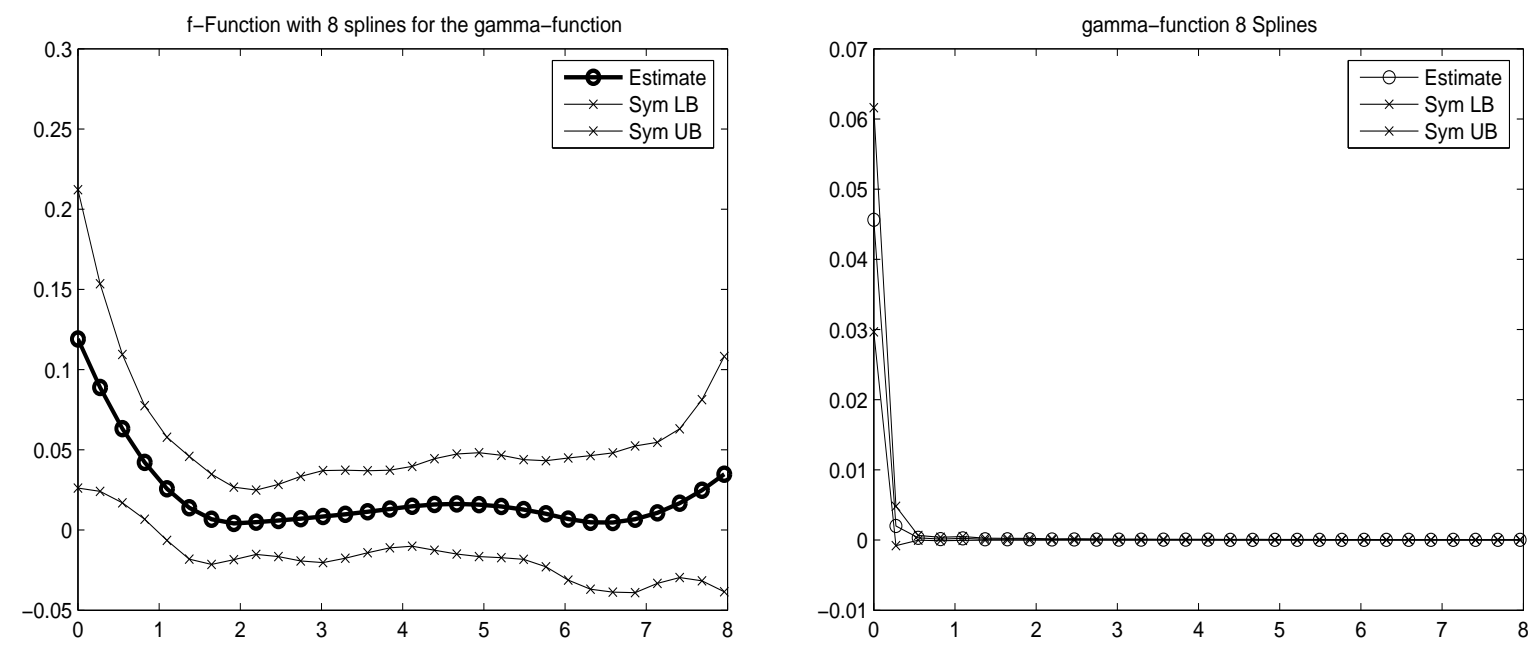

Figure 1: Conditional mean $(\hat{f}[$ left $])$ and covariance $(\hat{\gamma}[$ right $])$ functions based on age-structured human capital proportion, $D_{1}$. 

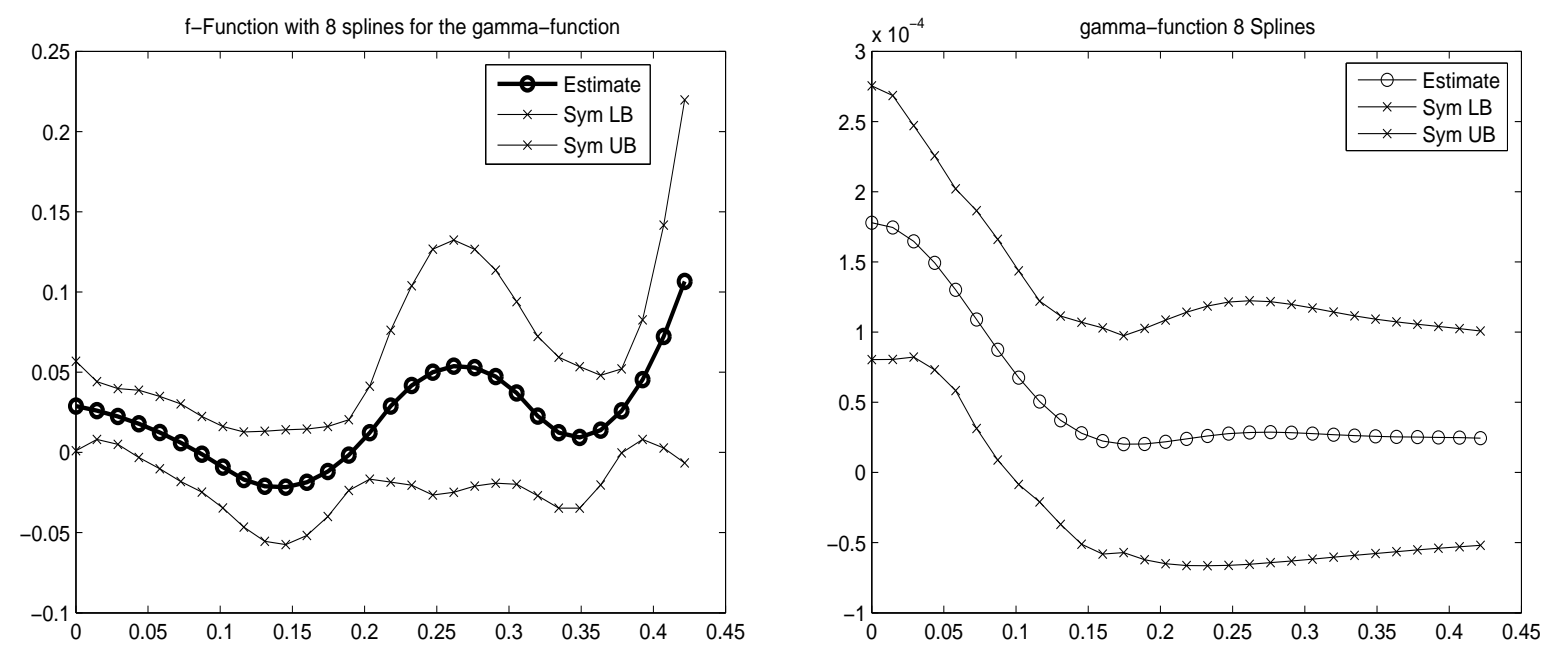

Figure 2: Conditional mean $(\hat{f}[\mathrm{left}])$ and covariance $(\hat{\gamma}[$ right $])$ functions based on elasticity of human capital input, $D_{2}$.

\section{References}

Boucekkine, R., D. de la Croix, and O. Licandro, 2002, Vintage Human Capital, Demographic Trends, and Endogenous Growth, Journal of Economic Theory, 104, 340-375.

Chen, X. and T.G. Conley, 2001, A New Semiparametric Spatial Model for Panel Time Series," Journal of Econometrics, 105, 59-83.

Conley, T.G. and B. Dupor, 2003, A Spatial Analysis of Sectoral Complementarity, Journal of Political Economy, 111(2), 311-352.

Durlauf, S.N., 1989, Output Persistence, Economic Structure and the Choice of Stabilization Policy, Brookings Papers on Economic Activity, 2, 69-116.

Ertur, C. and W. Koch, 2006, Regional Disparities in the European Union and the Enlargement Process: An Exploratory Spatial Data Analysis, 1995-2000, Annals of Regional Science, 40(4), 723-765.

Ertur, C. and W. Koch, 2007, Growth, Technological Interdependence and Spatial Externalities: Theory and Evidence, forthcoming in Journal of Applied Econometrics.

Fujita, M. and J.F. Thisse, 2002, Economics of agglomeration (Cambridge University Press).

Levy, D. and H. Dezhbakhsh, 2003, International evidence on output fluctuation and shock persistence, Journal of Monetary Economics, 50, 1499-1530.

Mello, M. and R. Guimaraes-Filho, 2007, A note on fractional stochastic convergence, Economics Bulletin, 3(16), 1-14. 
Raj, B., 1993, An international study of persistence in output: Parametric estimates using the data dependent systems approach, Empirical Economics, 18(1), 173-195. 